\title{
Occupancy patterns of prey species in a biological corridor and inferences for tiger population connectivity between national parks in Bhutan
}

\author{
Letro Letro, Klaus Fischer, Dorji Duba and Tandin Tandin
}

\begin{abstract}
Site occupancy models, accounting for imperfect detection and the influence of anthropogenic and ecological covariates, can indicate the status of species populations. They may thus be useful for exploring the suitability of landscapes such as biological corridors, to ensure population dispersal and connectivity. Using occupancy probability models of its principal prey species, we make inferences on landscape connectivity for the movement of the tiger Panthera tigris between protected areas in Bhutan. We used camera-trap data to assess the probability of site occupancy $(\Psi)$ of the sambar Rusa unicolor, wild boar Sus scrofa and barking deer Muntiacus muntjak in biological corridor no. 8, which connects two national parks in central Bhutan. At least one prey species was recorded at 17 out of 26 trapping locations. The probability of site occupancy was highest for the barking deer $(\Psi=0.52 \pm$ SE 0.09$)$ followed by sambar $(\Psi=0.49 \pm$ SE 0.03$)$ and wild boar $(\Psi=0.45 \pm$ SE 0.07). All three species had higher occupancy probability at lower altitudes. Sambar occupancy was greater farther from settlements and on steeper and/or south-facing slopes. Barking deer also had higher occupancy on south-facing slopes, and wild boar occurred mainly close to rivers. Our findings suggest that this biological corridor could facilitate dispersal of tigers. Protecting prey species, and minimizing anthropogenic disturbance and habitat fragmentation, are vital for tiger dispersal and thus functional connectivity amongst populations in this area.
\end{abstract}

Keywords Bhutan, biological corridor, dispersal, landscape connectivity, occupancy modelling, Panthera tigris, ungulates

LETro Letro* (Corresponding author, (iD) orcid.org/0000-0003-2042-4030) and KLAUS FisCHER $\dagger$ (D orcid.org/0000-0002-2871-246X) Zoological Institute and Museum, University of Greifswald, Loitzer Straße 26, D-17489 Greifswald, Germany. E-mail fr.lethro81@gmail.com

DorJi Duba Department of Forests and Park Services, Bhutan Tiger Centre, Gelephu, Bhutan

Tandin Tandin Department of Forests \& Park Services, Nature Conservation Division, Taba, Thimphu, Bhutan

${ }^{\star}$ Current address: Department of Forests \& Park Services, Nature Conservation Division, Taba, Thimphu, Bhutan

†Current address: Institute for Integrated Natural Sciences, University of Koblenz-Landau, Koblenz, Germany

Received 7 April 2020. Revision requested 5 June 2020.

Accepted 23 September 2020. First published online 14 June 2021.
Supplementary material for this article is available at doi.org/10.1017/So030605320000976

\section{Introduction}

T arge ungulates influence forest structure and functionLing (Gopalaswamy et al., 2012), and the density and spatial distribution of apex predators such as the tiger Panthera tigris. The occurrence of tigers is primarily determined by the abundance of ungulate prey (Karanth et al., 2004; Harihar \& Pandav, 2012), and by levels of human disturbance (Linkie et al., 2006). In the Himalayan region, ungulates such as the sambar Rusa unicolor, wild boar Sus scrofa, barking deer Muntiacus muntjak, chital Axis axis and gaur Bos gaurus are the principal prey of tigers, with some variations between localities and habitat types (Karanth et al., 2004; Harihar \& Pandav, 2012; Hayward et al., 2012; Tempa, 2017). These prey species constitute an important structural component of tiger habitats and movement corridors, and their occupancy is influenced by environmental parameters such as elevation, forest coverage, and distance from water, and by levels of human interference (Tempa, 2017).

Bhutan is a hotspot of wild felid diversity (Tempa et al., 2013; Dhendup \& Dorji, 2018), with the tiger being of particular conservation concern (DoFPS, 2015a). Tigers are widely distributed in Bhutan from subtropical to alpine regions (Tempa, 2017). The first nationwide tiger survey, using camera traps, was completed in 2015, with the number of tigers estimated to be 103 , at a density of 0.46 tigers per $100 \mathrm{~km}^{2}$ (DoFPS, 2015a). Tiger density was high (2-3 tigers per $100 \mathrm{~km}^{2}$ ) in protected areas in central Bhutan such as the Royal Manas and Jigme Singye Wangchuck National Parks (Tempa, 2017). In Bhutan, tigers successfully breed at altitudes from near sea level to $>4,000 \mathrm{~m}$ (Jigme \& Tharchen, 2012). Provided that corridors between tiger habitats ensure structural and functional connectivity, Bhutan could make a significant contribution towards global tiger conservation goals such as doubling global tiger numbers by 2022 (compared to 2010; GTRP, 2011). The functional connectivity of a landscape is determined by its structure and composition (Rudnick et al., 2012), and the term structural connectivity describes the physical characteristics of a landscape that facilitate or hamper wildlife movement, including topography, hydrology, vegetative cover and human land-use patterns (Metzger \& Décamps, 1997). 
Bhutan has 10 protected areas, including five national parks, four wildlife sanctuaries and one strict nature reserve (DoFPS, 2015b). Eight biological corridors, numbered 1-8, were established in 1999, to connect protected areas and facilitate wildlife movement and dispersal (Sherpa \& Norbu, 1999; Wangchuk, 2007). The biological corridors were designated based on vegetation cover derived from Landsat images, land-use maps and evidence of tiger occurrence. Evidence suggests corridors facilitate dispersal of smaller mammals and birds elsewhere (Littlewood et al., 2020), but the biological corridors in Bhutan were not validated with fieldwork, mainly because of a lack of trained personnel and resources (Thinley, 2010). To assess the functional connectivity of these biological corridors for the movement of large carnivores such as the tiger, it is important to document the occurrence of prey species, as a proxy for structural connectivity. Well managed biological corridors are likely to enhance dispersal of tigers and other carnivores, thus providing connectivity between habitats (Harihar \& Pandav, 2012; Letro \& Duba, 2019).

Species distribution models can be used to assess the impacts of ecological and anthropogenic covariates on the distribution and habitat use of species of conservation concern (Elith \& Leathwick, 2009). Environmental variables affect species distributions and can thus be used to predict distributions across landscapes. In addition, environmental variables such as habitat type or proximity to water influence fine-scale habitat use (Harihar \& Pandav, 2012), and can be used to identify essential conservation areas (Penjor et al., 2018, 2019) and guide conservation actions at the local level (Sunarto et al., 2012; Srivathsa et al., 2014).

Here, we use detection/non-detection data of prey species collected through camera trapping in Bhutan's biological corridor no. 8 for occupancy modelling (Mackenzie et al., 2002), to assess the probability of site occupancy of the tiger's principal prey species, accounting for imperfect detection. Our objectives were to ascertain occupancy probability and its determinants for three principal prey species (sambar, wild boar and barking deer), and to develop predictive distribution maps for the study area based on spatially explicit occupancy models for the three prey species, to assess landscape connectivity for tiger dispersal. No studies have previously been carried out on prey species distribution and habitat use for any of the biological corridors in Bhutan. Our study thus contributes to a better understanding of the role that biological corridors play in enhancing landscape connectivity in Bhutan.

\section{Study area}

We conducted this study in the parts of biological corridor no. 8 that connect Jigme Singye Wangchuck and Wangchuck Centennial National Parks, covering c. $240 \mathrm{~km}^{2}$
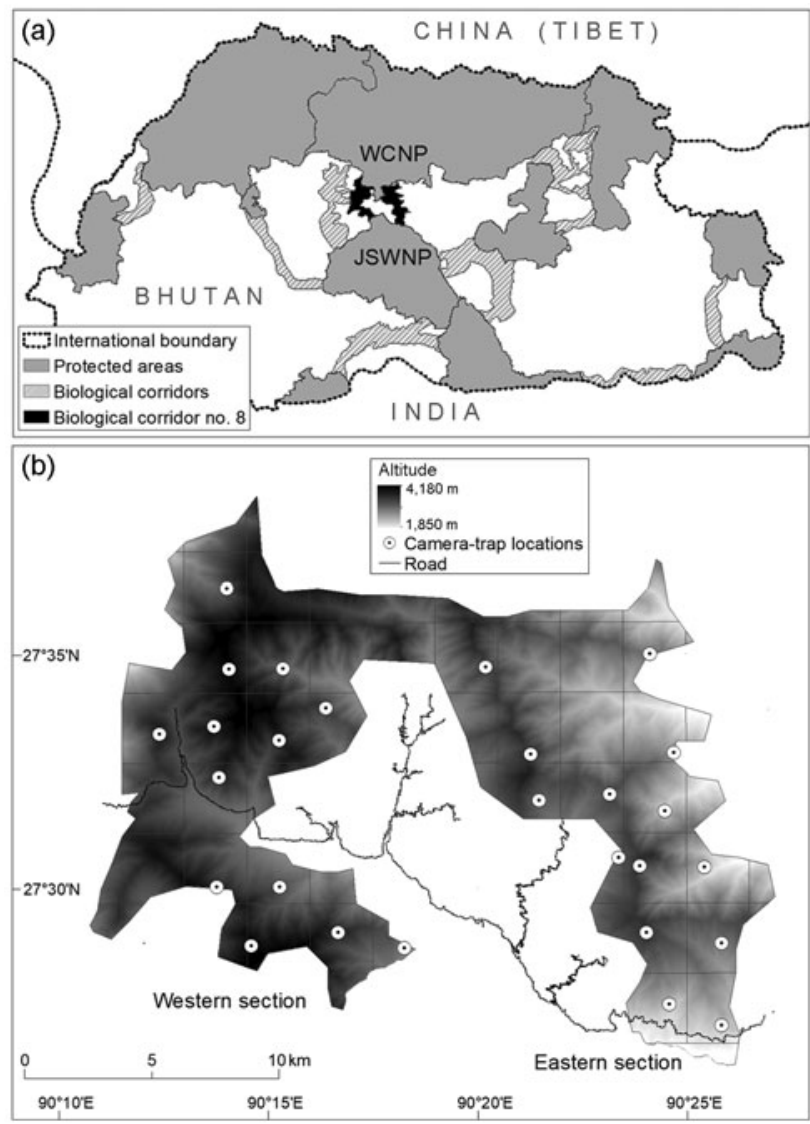

FIG. 1 (a) Biological corridor no. 8 in central Bhutan, connecting Jigme Singye Wangchuck National Park (JSWNP) and Wangchuck Centennial National Park (WCNP) and (b) location of camera traps in biological corridor no. 8 .

(Fig. 1). The area is at an altitude of $1,850-4,180 \mathrm{~m}$, with a warm-temperate climate, mean annual temperature of $14^{\circ} \mathrm{C}$ and a mean total annual rainfall of $1,956 \mathrm{~mm}$ (NCHM, 2018). The landscape is undulating and mainly covered with various forest types, including broadleaved, fir, blue pine Pinus wallichiana and mixed conifer forests, and alpine scrub. Past surveys documented the presence of apex predators such as the tiger, the common leopard Panthera pardus and the Asiatic black bear Ursus thibetanus, and several prey species including the sambar, wild boar, Himalayan serow Capricornis thar, barking deer, Himalayan goral Naemorhedus goral, musk deer Moschus chrysogaster and takin Budorcas taxicolor whitei (DoFPS, 2015a). Human land-use types in the study area comprise pastures and built-up areas (roads and permanent human settlements). Seasonal livestock grazing and collection of forest resources in and around the study area exert anthropogenic pressures on the biological corridor (Letro \& Fischer, 2020). The eastern and western sections of the corridor differ in the level of human interference, with more human settlements and roads, and more grazing pressure from domestic animals, in the western section. 
TABLE 1 The characteristics of the three ungulates that are the principal prey species of the tiger Panthera tigris in biological corridor no. 8 (Fig. 1), adapted from McShea et al. (2011).

\begin{tabular}{llll}
\hline & Sambar & Wild boar & Barking deer \\
Attribute & Rusa unicolor & $25-40$ & Muntjacus muntjak \\
\hline Body mass $(\mathrm{kg})$ & $180-260$ & $2.0-2.2$ & $20-30$ \\
Home range $\left(\mathrm{km}^{2}\right)$ & $0.1-1.0$ & $6-10$ & $1.5-2.5$ \\
Group size & $3-4$ & Unknown & $1-2$ \\
Birth season & May-Aug. & Browse, graze, rooting, omnivore & Nov.-May \\
Diet & Browse, ferns, grass, forbs & Unknown & Browse, forbs \\
Range in South Asia & $4,388,000 \mathrm{~km}^{2}$ & Unknown & $4,157,000 \mathrm{~km}^{2}$ \\
\% of range protected & 0.09 & Least Concern & 0.09 \\
IUCN Red List category & Vulnerable & & Least Concern \\
\hline
\end{tabular}

\section{Methods}

\section{Data collection}

To estimate the occupancy of tiger prey species, we conducted a camera-trap survey during March-June 2018. We divided the study area into 35 grid cells of $2.5 \times 2.5 \mathrm{~km}$, with grid cell size chosen to account for the expected daily movements of prey species, based on their known home range sizes (Table 1) and movement rates (Odden \& Wegge, 2007; Gopalaswamy et al., 2012; Thapa \& Kelly, 2016). Using a sufficiently large grid cell size is important, to minimize the risk of violating the assumption of closure when estimating occupancy (Mackenzie et al., 2002). We set up camera-trap stations in 27 of the 35 grid cells ( $77 \%), 14$ and 13 in the eastern and western sections, respectively, at 2,085-3,900 m altitude (Fig. 1). To increase the probability of photo-capturing prey species and tigers, we installed camera traps along game trails leading to streams and salt licks, and at trail junctions and ridge tops. We placed one automated HCO-ScoutGuard (Professional Trapping Supplies, Molendinar, Australia) camera-trap unit at each station, fastened on a wooden post $45 \mathrm{~cm}$ above ground level, and at a distance of c. $2.0-3.5 \mathrm{~m}$ from the centre of the trail. Camera traps were active during 27 March-6 June 2018 , for $33^{-5} 5$ days per location. We recorded the geographical coordinates of the location of each camera-trap station. We defined independent images of a species as those that were taken at least 5 minutes apart.

\section{Data analysis}

Occupancy data may be affected by the detectability of target species. We examined the impact of trap effort (the number of days the camera trap was active) and study site (eastern vs western section), as we expected these covariates to influence detection probability of prey species. With regard to occupancy probability, we tested the impact of various site covariates, including altitude, slope, aspect, land-use type, and distances to the nearest river, protected area, road and human settlement. We selected these variables based on prior studies of the tiger and its prey in this region (Kushwaha et al., 2004; Linkie et al., 2006; Kanagaraj et al., 2011; Harihar \& Pandav, 2012; Tempa, 2017). Altitude, aspect, slope and distance to river characterize physical properties of the environment, whereas land-use type and distances to the nearest protected area, road and settlement describe human impact. We determined the value of each site covariate as the mean of raster cells within circles of $500 \mathrm{~m}$ radius around each camera-trap station, using the zonal statistics tool in QGIS 3.2.1 (QGIS Development Team, 2018). We extracted altitude, slope, and aspect values from digital elevation raster data (USGS, 2018). We categorized land-use types as built-up area, farmland, broadleaved forest, conifer forest, mixed conifer forest, meadow, alpine scrub, and rocky outcrop. To determine land-use types and locations of roads, protected areas and rivers, we used the Bhutan land-use and land-cover data 2016 (FRMD, 2017). We measured distances using the Euclidean distance tool in QGIS.

Occupancy models using detection/non-detection data have two inferences: the probability of detection $(\mathrm{P}$; the probability that a species appears during count statistics) and the probability of occupancy ( $\Psi$; the probability that the species occupies a random site in a given time period; MacKenzie et al., 2006). We generated detection histories ( 1 for detection, o for non-detection) for each species at each camera trap over the respective trapping period, using ReNamer 6.8 (Sanderson \& Harris, 2013). For occupancy modelling, we selected the optimal number of trap-days (i.e. sampling period) for each prey species based on the $\chi^{2}$ goodness-of-fit test of the multivariate model (MacKenzie \& Bailey, 2004): 10 days for sambar, 12 for wild boar and 15 for barking deer (Supplementary Table 1).

For each prey species, we imported the detection history over the optimal sampling period and the various site covariates into PRESENCE 2.12.17 (Hines, 2006), to run singleseason single-species occupancy models (Mackenzie et al., 2002). We z-standardized all continuous covariates to a 
TABLE 2 Detection probability (P) models, with the study site (eastern vs western section of the corridor) and trap effort (total number of active camera-trap days) as detection covariates, and with the Akaike information criterion (AIC), difference between AIC and the best-performing model $(\triangle \mathrm{AIC})$, model weight and likelihood, number of parameters $(K)$, and twice the negative loglikelihood $(-2 \operatorname{LogLik})$ for each model. Occupancy probability $(\Psi)$ was held constant.

\begin{tabular}{lllllll}
\hline Model & AIC & AAIC & $\begin{array}{l}\text { Model } \\
\text { weight }\end{array}$ & $\begin{array}{l}\text { Model } \\
\text { likelihood }\end{array}$ & $K$ & -2LogLik \\
\hline $\begin{array}{l}\text { Sambar } \\
\text { P(Site }\end{array}$ & 76.58 & 0.00 & 0.33 & 1.00 & 4 & 68.58 \\
$\quad \quad+$ Effort) & & & & & & \\
P(Effort) & 77.17 & 0.59 & 0.24 & 0.74 & 2 & 73.17 \\
P(Site) & 77.27 & 0.69 & 0.24 & 0.71 & 3 & 71.27 \\
P(.) & 77.42 & 0.84 & 0.21 & 0.66 & 2 & 73.42 \\
Barking deer & & & & & & \\
P(Effort) & 88.00 & 0.00 & 0.40 & 1.00 & 2 & 84.00 \\
P(.) & 88.09 & 0.09 & 0.38 & 0.96 & 2 & 84.09 \\
P(Site) & 89.91 & 1.91 & 0.15 & 0.38 & 3 & 83.91 \\
P(Site & 91.85 & 3.85 & 0.06 & 0.15 & 4 & 83.85 \\
$\quad+$ Effort) & & & & & & \\
$\quad$ Wild boar & & & & & & \\
P(Effort) & 83.24 & 0.00 & 0.53 & 1.00 & 2 & 79.24 \\
P(Site) & 84.97 & 1.73 & 0.22 & 0.42 & 3 & 78.97 \\
P(Site & 85.89 & 2.65 & 0.15 & 0.27 & 4 & 77.89 \\
$\quad+$ Effort) & & & & & & \\
P(.) & 86.58 & 3.34 & 0.10 & 0.19 & 2 & 82.58 \\
\hline
\end{tabular}

TABLE 3 Estimates of $\beta$-coefficient values for covariates influencing the detection probability $(\mathrm{P})$ of prey species in the biological corridor in the top-ranking models (Table 2).

\begin{tabular}{llll}
\hline & $\begin{array}{l}\beta \pm \mathrm{SE} \\
\text { (eastern } \\
\text { section) }\end{array}$ & $\begin{array}{l}\beta \pm \mathrm{SE} \\
\text { (western } \\
\text { section) }\end{array}$ & $\begin{array}{l}\beta \pm \mathrm{SE} \\
\text { (Effort) }\end{array}$ \\
\hline $\begin{array}{l}\text { Sambar } \\
\text { P(Site+Effort) }\end{array}$ & $-0.93 \pm 0.58$ & $0.66 \pm 0.57$ & $0.85 \pm 0.43$ \\
$\begin{array}{l}\text { Barking deer } \\
\text { P(Effort) }\end{array}$ & & & $0.41 \pm 0.37$ \\
$\begin{array}{l}\text { Wild boar } \\
\text { P(Effort) }\end{array}$ & & & $0.66 \pm 0.35$ \\
\hline
\end{tabular}

mean of zero and one standard deviation using the formula $z=\left(x-x^{\prime}\right) / S D$, where $x$ is the individual value, $x^{\prime}$ the mean of the factor, and $S D$ the standard deviation, to improve model convergence (Sunarto et al., 2012). We tested covariates for collinearity using Pearson correlations in $R$ 3.5.1 ( $\mathrm{R}$ Core Team, 2018), and for correlated covariates $(|r|>0.6)$ removed one of the two covariates, to avoid biased estimates (Dormann et al., 2013). There were high correlations between land-use type and elevation, distance to protected area and distance to river, and distance to road and distance to settlement (Supplementary Table 2). We retained the covariates that performed better in univariate occupancy models, based on a lower value of the Akaike information criterion (AIC), for multivariate modelling (Supplementary Table 3), and thus excluded land-use type, and distances from protected area and road.

We used a two-step approach (Penjor et al., 2018) to estimate probability of detection $(\mathrm{P})$ and probability of species occupancy $(\Psi)$. Firstly, we modelled detection probability (P) for each principal prey species in relation to study site (eastern vs western section) and trap effort. To identify the covariates that significantly affected detection probability, we used both univariate and multivariate detection probability models, keeping site occupancy $(\Psi)$ constant. Secondly, we modelled the probability of site occupancy ( $\Psi)$ for each species in relation to the covariates elevation, slope, aspect, distance to settlement and distance to river. In all univariate occupancy models, detection probability was kept constant such as $\Psi$ (covariate), $\mathrm{P}($.$) . Subsequently,$ we built best models based on AIC values (Burnham \& Anderson, 2004), considering all multivariate models with $\Delta \mathrm{AIC}<2$ to be strongly supported by the data. We used model averaging techniques to determine the grid cell specific probabilities of occupancy considering all competing models. We examined model fit using goodness-of-fit tests with 10,000 bootstrapping steps. We used the mean untransformed beta coefficient estimate from the best multivariate model to predict site occupancy of the three prey species. The value of untransformed coefficients reflects the magnitude and direction of their influence on occupancy

TABLE 4 Estimates of $\beta$-coefficient values for covariates influencing the occupancy of prey species $(\Psi)$ in the biological corridor based on the top-ranking models (Table 2).

\begin{tabular}{|c|c|c|c|c|c|}
\hline Model $^{1}$ & $\begin{array}{l}\beta \pm \mathrm{SE} \\
\text { (Elevation) }\end{array}$ & $\begin{array}{l}\beta \pm \mathrm{SE} \\
\text { (Distance to settlement) }\end{array}$ & $\begin{array}{l}\beta \pm \mathrm{SE} \\
\text { (Aspect) }\end{array}$ & $\begin{array}{l}\beta \pm \mathrm{SE} \\
\text { (Distance to river) }\end{array}$ & $\begin{array}{l}\beta \pm \mathrm{SE} \\
\text { (Slope) }\end{array}$ \\
\hline \multicolumn{6}{|l|}{ Sambar } \\
\hline $\begin{array}{l}\Psi(\text { Slope }+ \text { Aspect }+ \text { Settlement }) \\
\text { P(Site+Effort })\end{array}$ & & $0.20 \pm 0.64$ & $-0.02 \pm 0.57$ & & $1.28 \pm 0.74$ \\
\hline \multicolumn{6}{|l|}{ Barking deer } \\
\hline$\Psi($ Elevation + Aspect $), \mathrm{P}($ Effort $)$ & $-1.54 \pm 0.96$ & & $-0.59 \pm 0.58$ & & \\
\hline \multicolumn{6}{|l|}{ Wild boar } \\
\hline$\Psi($ Elevation+River), $\mathrm{P}$ (Effort) & $-2.64 \pm 1.60$ & & & $-0.73 \pm 0.83$ & \\
\hline
\end{tabular}

${ }^{1}$ River, distance to nearest river; Settlement, distance to nearest settlement. 
probability. We produced predictive maps for the entire study area using QGIS, based on inferences from the model-averaged outputs for the sampled grid cells.

\section{Results}

Of the 27 camera traps deployed, we retrieved 26 (one was lost); 14 from the eastern and 12 from the western section. The total trap effort was 1,080 trap-days. At least one prey species was recorded at 17 out of 26 camera-trap locations, yielding 368 independent images. Sambar was recorded at nine, barking deer at 11 and wild boar at 10 locations, resulting in naïve (survey-based) occupancy probabilities of $0.35,0.42$ and 0.39 , respectively. Tigers were detected at five cameratrap locations.

The detection probability $(\mathrm{P})$ of all three prey species was positively affected by trap effort (Tables $2 \& 3$ ). The likelihood-based analysis of sambar occupancy showed the highest support for the model that included slope, aspect and distance to the nearest settlement (Table 4), with occupancy being higher in areas that were further away from settlements, and on steeper and/or south-facing slopes. For barking deer, the model that included altitude and aspect performed best, and for wild boar, the model that included altitude and distance to the next river had the highest support. Occupancy of both barking deer and wild boar was higher at lower elevations. Barking deer occupancy was higher on south-facing slopes, and wild boar occurred mainly closer to rivers. Occupancy probability of barking deer was higher in the eastern (0.62 \pm SE 0.06$)$ than in the western (0.35 \pm SE 0.07) section (Fig. 2b). This was also the case for wild boar (eastern $0.64 \pm$ SE 0.09 , western $0.24 \pm$ SE 0.08 ; Fig. 2c). Sambar occupancy was higher in the western (0.57 \pm SE 0.07) than in the eastern section (o.44 \pm SE 0.06; Fig. 2a) The model-averaged probability of occupancy $(\Psi)$ derived from top-ranked models (Table 5) was $0.49 \pm \mathrm{SE}$ 0.03 for sambar, $0.52 \pm$ SE 0.09 for barking deer and $0.45 \pm$ SE 0.07 for wild boar. In all cases, this was higher than the naïve occupancy (Fig. 3).

\section{Discussion}

Our findings on the occurrence of the principal prey species of the tiger suggest that biological corridor no. 8 provides sufficient structural connectivity between Jigme Singye Wangchuck National Park and Wangchuck Centennial National Park to facilitate tiger movements between these areas. Overall, prey occupancy was relatively high in the study area, with at least one prey species photo-trapped at 17 out of 26 grid cells, and naïve occupancy for each species 0.35-0.42. Occupancy estimates were highest for barking deer, followed by sambar and wild boar. The fact that habitat covariates retained in the best models differed between
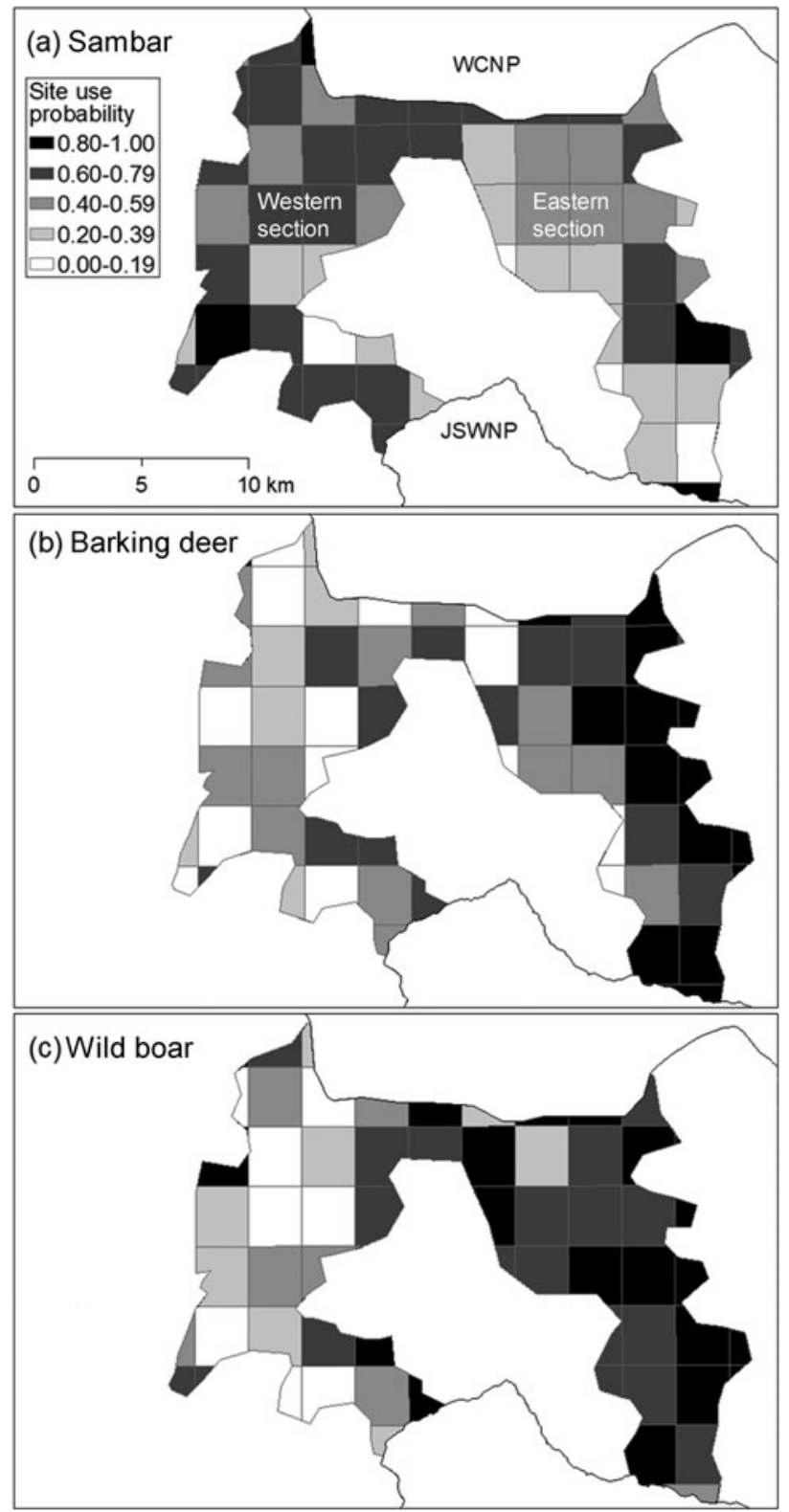

FIG. 2 Predicted occupancy probability of the principal prey species of the tiger Panthera tigris: (a) sambar Rusa unicolor, (b) barking deer Muntjacus muntjak and (c) wild boar Sus scrofa in biological corridor no. 8, which connects Jigme Singye Wangchuck National Park (JSWNP) and Wangchuck Centennial National Park (WCNP).

species suggests niche partitioning between these three sympatric ungulates. This is important for maintaining a balance between predator species abundance and resource availability (Cooke et al., 2016).

Barking deer and wild boar, and to a lesser extent sambar, preferred lower elevations (for sambar, see models in Table 3 with $\triangle$ AIC $<2$ ). This corroborates Tempa's (2017) findings for these species across Bhutan, showing a negative influence of elevation on occupancy. All three species have a wide altitudinal range, but with few records above $3,000 \mathrm{~m}$ for barking deer and wild boar (Oliver \& Leus, 2015; 
TABLE 5 Multivariate model selection results for the effects of various covariates on the occupancy probability $(\Psi)$ of principal prey species. The table shows the Akaike information criterion (AIC), difference between AIC and the best-performing model ( $\triangle$ AIC), model weight and likelihood, number of parameters $(K)$, and twice the negative log-likelihood ( $-2 \operatorname{LogLik})$ for each model. The top three models for each species are shown.

\begin{tabular}{|c|c|c|c|c|c|c|}
\hline Model $^{1}$ & AIC & $\Delta \mathrm{AIC}$ & Model weight & Model likelihood & $K$ & $-2 \operatorname{LogLik}$ \\
\hline \multicolumn{7}{|l|}{ Sambar } \\
\hline$\Psi($ Slope + Aspect+Settlement $), \mathrm{P}($ Site+Effort $)$ & 75.73 & 0.00 & 0.39 & 1.00 & 6 & 63.73 \\
\hline$\Psi($ Elevation + Aspect $), \mathrm{P}($ Site+Effort $)$ & 76.21 & 0.48 & 0.31 & 0.78 & 5 & 66.21 \\
\hline$\Psi$ (Elevation, Settlement), P(Site+Effort) & 76.31 & 0.58 & 0.29 & 0.75 & 5 & 66.31 \\
\hline \multicolumn{7}{|l|}{ Barking deer } \\
\hline$\Psi($ Elevation + Aspect $), \mathrm{P}$ (Effort) & 83.64 & 0.00 & 0.44 & 1.00 & 3 & 77.64 \\
\hline$\Psi($ Elevation+Road), $\mathrm{P}$ (Effort) & 84.48 & 0.84 & 0.29 & 0.66 & 3 & 78.48 \\
\hline$\Psi($ Elevation+River), $\mathrm{P}$ (Effort) & 84.59 & 0.95 & 0.27 & 0.62 & 3 & 78.59 \\
\hline \multicolumn{7}{|l|}{ Wild boar } \\
\hline$\Psi($ Elevation+River), $\mathrm{P}($ Effort $)$ & 72.98 & 0.00 & 0.25 & 1.00 & 3 & 66.98 \\
\hline$\Psi($ Elevation+Slope $), \mathrm{P}($ Effort $)$ & 73.17 & 0.19 & 0.23 & 0.91 & 3 & 67.17 \\
\hline$\Psi($ Elevation+Road), P(Effort) & 73.60 & 0.62 & 0.18 & 0.73 & 3 & 67.60 \\
\hline
\end{tabular}

${ }^{1}$ River, distance to nearest river; Road, distance to nearest road; Settlement, distance to nearest settlement.

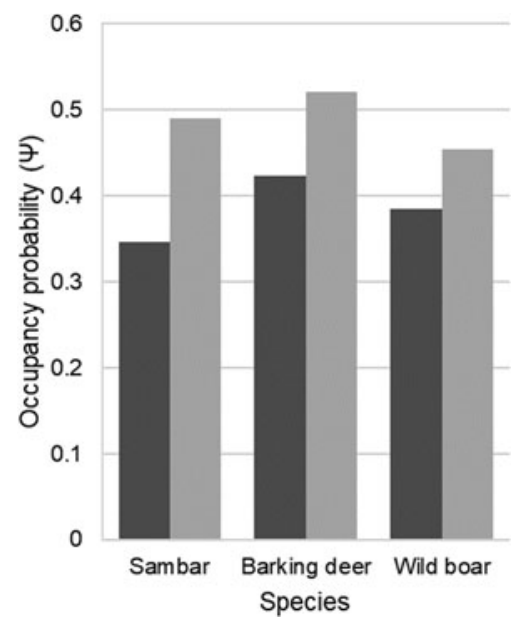

FIG. 3 Naïve (dark grey) and modelled (light grey) occupancy for the principal prey species of the tiger Panthera tigris in biological corridor no. 8.

Timmins et al., 2016). Sambar may occur up to $3,800 \mathrm{~m}$ (Timmins et al., 2015). We recorded sambar, barking deer and wild boar at a maximum of 3,686, 3,652, and 3,521 m, respectively. Sambar and barking deer occupancies were higher on south-facing slopes (see also Forsyth et al., 2009 for sambar deer in Australia). It is unknown whether southfacing slopes are preferred for thermal reasons (temperature, wind shelter; Moore, 1994) or associated vegetation structure and composition. Sambar deer were recorded more frequently on steeper slopes, supporting the findings of Johnsingh et al. (2004) and Kushwaha et al. (2004), who documented a preference for hilly terrain. This could be because such areas are less accessible for people. Wild boar occupancy was positively affected by rivers, reflecting the species' preference for moist habitats such as riverine forests or marshes (Graves, 1984). In addition, agricultural fields, to which wild boars are often attracted, are generally located near rivers in Bhutan. Elevation had a stronger effect on the occurrence of all three species than land-use or forest type, which is surprising as vegetation type is expected to be an important factor affecting the availability of shelter and food (e.g. Moore, 1994). However, this finding agrees with an earlier study on sambar (Forsyth et al., 2009), and can probably be explained by the fact that all three species are opportunistic generalists and able to thrive in a broad range of forest types and environmental conditions (Oliver \& Leus, 2015; Timmins et al., 2015, 2016).

Sambar showed a slightly higher occupancy in the western section of the corridor, whereas barking deer and wild boar were more common in the east. The overall higher prey occupancy in the east is probably related to its lower mean elevation and proximity to a river and agricultural fields (the latter located outside the study area). In Bhutan, the relative abundance of wild boar and barking deer is highest in areas close to croplands (Thinley et al., 2017). Both species regularly damage agricultural fields (Wang et al., 2006) and are relatively tolerant of human disturbance (Tempa, 2017). In addition, the high intensity of seasonal grazing in the western section (Letro \& Fischer, 2020) may negatively affect prey species abundance.

The occupancy patterns of these three principal prey species of the tiger suggest that biological corridor no. 8 is potentially important for facilitating tiger movements between the two adjoining national parks. The eastern section of the corridor may be more suitable for tiger movements because of higher probability of prey occupancy. However, tigers were recorded at three and two locations in the eastern and western sections, respectively. This could be because of variation in other factors such as the availability of domestic prey, which also influence tiger movements (Bagchi et al., 2003; Sunarto et al., 2012). Letro \& Fischer (2020) 
reported frequent incidences of livestock depredation by tigers in the corridor. To ensure the connectivity of tiger populations in the two national parks through this biological corridor, we recommend assessing prey species density, and protection of prey species through patrolling. The management of the biological corridor should be enhanced through the development of conservation management plans. These should include adequate land-use planning and local forest management plans, to reduce anthropogenic disturbances and minimize habitat fragmentation.

Acknowledgements We thank the management of Jigme Singye Wangchuck National Park and the Nature Conservation Division, Department of Forests and Park Services, for their support; the National Geographic Society, the Mohamed Bin Zayed Species Conservation Fund and The Rufford Foundation for funding; Wangchuk Dorji, Tshering Dorji and Thinley Lhendup for assistance with data collection; and the anonymous reviewers and the editors for their help with improving the article.

Author contributions Study conception and design: LL, KF; securing research funds: LL; data collection: LL, DD; data analysis: LL, KF, TT; writing: all authors.

\section{Conflict of interest None.}

Ethical Standards This research abided by the Oryx guidelines on ethical standards and was approved by the Research Steering Committee of the Department of Forests and Park Services, Ministry of Agriculture and Forests of the Royal Government of Bhutan (application ID: 5841017285A0C0133DD581). The fieldwork was conducted with approval of the Honourable Director, Department of Forests and Park Services, Thimphu, Bhutan (no. DoFPS/NCD/ Adm-01/2018/8269).

\section{References}

Bagchi, S., Goyal, S.P. \& Sankar, K. (2003) Prey abundance and prey selection by tigers (Panthera tigris) in a semi-arid, dry deciduous forest in western India. Journal of Zoology, 260, 285-29o.

Burnham, K.P. \& Anderson, D.R. (2004) Multimodel inference: understanding AIC and BIC in model selection. Sociological Methods and Research, 33, 261-304.

Cooke, R.S.C., Woodfine, T., Petretto, M. \& Ezard, T.H.G. (2016) Resource partitioning between ungulate populations in arid environments. Ecology and Evolution, 6, 6354-6365.

Dhendup, T. \& Dorji, R. (2018) Occurrence of six felid species outside protected areas in Bhutan. Cat News, 67, 37-39.

DoFPS (2015a) Counting the Tigers in Bhutan: Report on the National Tiger Survey of Bhutan 2014-2015. Department of Forests and Park Services, Thimphu, Bhutan.

DoFPS (2015b) Protected Areas of Bhutan. 1st edition. Department of Forests and Park Services, Thimphu, Bhutan.

Dormann, C.F., Elith, J., Bacher, S., Buchmann, C., Carl, G., CArré, G. et al. (2013) Collinearity: A review of methods to deal with it and a simulation study evaluating their performance. Ecography, 36, 27-46.

Elith, J. \& Leathwick, J.R. (2009) Species distribution models: ecological explanation and prediction across space and time. Annual Review of Ecology, Evolution, and Systematics, 40, 677-697.
Forsyth, D.M., McLeod, S.R., Scroggie, M.P. \& White, M.D. (2009) Modelling the abundance of wildlife using field surveys and GIS: Non-native sambar deer (Cervus unicolor) in the Yarra Ranges, south-eastern Australia. Wildlife Research, 36, 231-241.

FRMD (2017) Land Use and Land Cover of Bhutan 2016, Maps and Statistics. Forester Resources Management Division, Department of Forests and Park Service, Thimphu, Bhutan.

Gopalaswamy, A.M., Karanth, K.U., Kumar, N.S. \& Macdonald, D.W. (2012) Estimating tropical forest ungulate densities from sign surveys using abundance models of occupancy. Animal Conservation, 15, 669-679.

Graves, H.B. (1984) Behavior and ecology of wild and feral swine (Sus scrofa). Journal of Animal Science, 58, 482.

GTRP (2011) Global Tiger Recovery Program (2010-2022). Global Tiger Initiative Secretariat, The World Bank, Washington, DC, USA. documents1.worldbank.org/curated/en/874191468331048098/pdf/ 732050WPooBox30110FinaloVersionoEng.pdf [accessed 8 August 2018].

HARIHAR, A. \& PANDAV, B. (2012) Influence of connectivity, wild prey and disturbance on occupancy of tigers in the human-dominated western Terai Arc landscape. PLOS ONE, 7, e40105.

Hayward, M.W., Jedrzejewski, W. \& Jedrzewska, B. (2012) Prey preferences of the tiger Panthera tigris. Journal of Zoology, 286, 221-231.

Hines, J.E. (2006) PRESENCE - Software to Estimate Patch Occupancy and Related Parameters. U.S. Geological Survey, Reston, Virginia, USA. mbr-pwrc.usgs.gov/software/presence.html [accessed 8 August 2018].

Jigme, K. \& Tharchen, L. (2012) Camera-trap records of tigers at high altitudes in Bhutan. CATnews, 56, 14-15.

Johnsingh, A.J.T., QuReshi, Q., Goyal, S.P., Rawat, G.S., Ramesh, K., DAvid, A. et al. (2004) Conservation Status of Tiger and Associated Species in the Terai Arc Landscape, India. RR-04/oo1, Wildlife Institute of India, Dehradun, India.

Kanagaraj, R., Wiegand, T., Kramer-Schadt, S., Anwar, M. \& GOYAL, S.P. (2011) Assessing habitat suitability for tiger in the fragmented Terai Arc Landscape of India and Nepal. Ecography, 34, 970-981.

Karanth, K.U., Nichols, J.D., Kumar, N.S., Link, W.A. \& Hines, J.E. (2004) Tigers and their prey: predicting carnivore densities from prey abundance. Proceedings of the National Academy of Sciences of the United States of America, 101, 4854-4858.

Kushwaha, S.P.S., Khan, A., Habib, B., Quadri, A. \& Singh, A. (2004) Evaluation of sambar and muntjak habitats using geostatistical modelling. Current Science, 86, 1390-1400.

Letro, L. \& Duba, D. (2019) Clouded leopard in biological corridor of Bhutan, an opportunity for population dispersal. CATnews, $69,34-35$.

Letro, L. \& Fischer, K. (2020) Livestock depredation by tigers and people's perception towards conservation in a biological corridor of Bhutan and its conservation implications. Wildlife Research, $47,309-316$.

Linkie, M., Chapron, G., Martyr, D.J., Holden, J. \& LeaderWilliams, N. (2006) Assessing the viability of tiger subpopulations in a fragmented landscape. Journal of Applied Ecology, 43, 576-586.

Littlewood, N.A., Rocha, R., Smith, R.K., Martin, P.A., Lockhart, S.L., Schoonover, R.F. et al. (2020) Terrestrial Mammal Conservation: Global Evidence for the Effects of Interventions for Terrestrial Mammals Excluding Bats and Primates. Synopses of Conservation Evidence Series. University of Cambridge, Cambridge, UK. conservationevidence.com/actions/2576 [accessed 30 July 2020].

Mackenzie, D.I. \& Bailey, L.L. (2004) Assessing the fit of site-occupancy models. Journal of Agricultural, Biological, and Environmental Statistics, 9, 300-318. 
Mackenzie, D.I., Nichols, J.D., Lachman, G.B., Droege, S., Andrew, J. \& LANGTimm, C.A. (2002) Estimating site occupancy rates when detection probabilities are less than one. Ecology, 83, 2248-2255.

MacKenzie, D.I., Nichols, J.D., Royle, J.A., Pollock, K.H., Bailey, L.L. \& Hines, J.E. (2006) Occupancy Estimation and Modeling: Inferring Patterns and Dynamics of Species Occurrence. Academic Press, Burlington, USA.

McShea, W.J., Davies, S.J. \& Bhumpakphan, N. (2011) The Ecology and Conservation of Seasonally Dry Forests in Asia. Smithsonian Institution Scholarly Press, Washington, DC, USA.

Metzger, J. \& Décamps, H. (1997) The structural connectivity threshold: an hypothesis in conservation biology at the landscape scale. Acta Oecologica, 18, 1-12.

Moore, I. (1994) Habitat use and activity patterns of sambar deer, Cervus unicolor, in the Bunyip Sambar Enclosure. MSc thesis, The University of Melbourne, Melbourne, Australia.

NCHM (2018) Climate Data Book of Bhutan 2018. National Center for Hydrology and Meteorology, Department of Energy, Thimphu, Bhutan.

Odden, M. \& Wegge, P. (2007) Predicting spacing behavior and mating systems of solitary cervids: A study of hog deer and Indian muntjac. Zoology, 110, 261-270.

Oliver, W. \& Leus, K. (2015) Sus scrofa. In The IUCN Red List of Threatened Species 2019: e.T41775A10559847. dx.doi.org/10.2305/ IUCN.UK.2019-3.RLTS.T41775A44141833.en [accessed 12 April 2018].

Penjor, U., Macdonald, D.W., Wangchuk, S., Tandin, T. \& Tan, C.K.W. (2018) Identifying important conservation areas for the clouded leopard Neofelis nebulosa in a mountainous landscape: inference from spatial modeling techniques. Ecology and Evolution, 8, 4278-4291.

Penjor, U., Tan, C.K.W., Wangdi, S. \& Macdonald, D.W. (2019) Understanding the environmental and anthropogenic correlates of tiger presence in a montane conservation landscape. Biological Conservation, 238, 108196.

QGiS Development Team (2018) QGIS Geographic Information System. Open Source Geospatial Foundation Project. qgis.osgeo.org [accessed 8 August 2018].

R Core Team (2018) R: A Language and Environment for Statistical Computing. R Foundation for Statistical Computing, Vienna, Austria. r-project.org [accessed 18 July 2018].

Rudnick, D., Ryan, M.G., Harmon, M.E., Birdsey, R.A., Giardina, C.P., Heath, L.S. et al. (2012) The role of landscape connectivity in planning and implementating conservation and restoration priorities. Issue in Ecology, 13, 1-16.

Sanderson, J.J.G. \& Harris, G. (2013) Automatic data organization, storage, and analysis of camera trap pictures. Journal of Indonesian Natural History, 1, 11.
Sherpa, M.N. \& Norbu, U.P. (1999) Linking protected areas for ecosystem conservation: a case study from Bhutan. Parks, $3,35-45$.

Srivathsa, A., Karanth, K.K., Jathanna, D., Kumar, N.S. \& Karanth, K.U. (2014) On a dhole trail: examining ecological and anthropogenic correlates of dhole habitat occupancy in the Western Ghats of India. PLOS ONE, 9, e106213.

Sunarto, S., Kelly, M.J., Parakkasi, K., Klenzendorf, S., Septayuda, E. \& Kurniawan, H. (2012) Tigers need cover: multi-scale occupancy study of the big cat in Sumatran forest and plantation landscapes. PLOS ONE, 7, e30859.

Tempa, T. (2017) The Ecology of Montane Bengal Tigers (Panthera tigris tigris) in the Himalayan Kingdom of Bhutan. $\mathrm{PhD}$ thesis, University of Montana, Missoula, USA.

Tempa, T., Hebblewhite, M., Mills, L.S., Wangchuk, T.R., Norbu, N., Wangchuk, T. et al. (2013) Royal Manas National Park, Bhutan: a hot spot for wild felids. Oryx, 47, 207-210.

Thapa, K. \& Kelly, M.J. (2016) Prey and tigers on the forgotten trail: high prey occupancy and tiger habitat use reveal the importance of the understudied Churia habitat of Nepal. Biodiversity and Conservation, 26, 593-616.

Thinley, P. (2010) Technical comments on the design and designation of biological corridors in Bhutan: global to national perspectives. Journal of Renewable Natural Resources, Bhutan, 6, 91-106.

Thinley, P., Lassoie, J.P., Morreale, S.J., Curtis, P.D., Rajaratnam, R., Vernes, K. et al. (2017) High relative abundance of wild ungulates near agricultural croplands in a livestockdominated landscape in Western Bhutan: implications for crop damage and protection. Agriculture, Ecosystems and Environment, 248, 88-95.

Timmins, R., Kawanishi, K., Giman, B., Lynam, A., Chan, B., Steinmetz, R. et al. (2015) Rusa unicolor (errata version published in 2015). In The IUCN Red List of Threatened Species 2015: e.T41790A85628124. dx.doi.org/10.2305/IUCN.UK.2015-2.RLTS. T41790A22156247.en [accessed 18 January 2021].

Timmins, R.J., Duckworth, J. \& Hedges, S. (2016) Muntiacus muntjak. In The IUCN Red List of Threatened Species 2016: e.T42190A56005589. dx.doi.org/10.2305/IUCN.UK.2016-1.RLTS. T42190A56005589.en [accessed 10 April 2018].

USGS (2018) Shuttle Radar Topography Mission. U.S. Geological Survey, Reston, USA. usgs.gov [accessed 13 January 2018].

WANG, S.W., Curtis, P.D. \& Lassoie, J.P. (2006) Farmer perceptions of crop damage by wildlife in Jigme Singye Wangchuck National Park, Bhutan. Wildife Society Bulletin, 34, 359-365.

WANGCHuK, S. (2007) Maintaining ecological resilience by linking protected areas through biological corridors in Bhutan.

Tropical Ecology, 48, 177-187. 